\title{
El arte del buen casar: matrimonio y viudedad en el siglo XVIII valenciano ${ }^{2}$
}

\section{The good marrying art: marriage and widowhood in the valencian 18th century}

\section{RESUMEN}

Gracias al análisis de diversos capítulos matrimoniales, testamentos, pleitos, poderes y otra documentación, hemos realizado una breve radiografía del proceso matrimonial nobiliario, con sus causas y consecuencias para la mujer, en el Reino de Valencia del siglo XVIII. Siendo estos acuerdos entre familias uno de los elementos clave en las estrategias de consolidación y ascenso nobiliario, reciben una atención especial y un trabajo hasta el detalle antes de las nupcias. La documentación muestra diversos procesos que reforzaban la autoridad paterna y la prioridad del ascenso del linaje. Asimismo, dada la dependencia de la mujer respecto al varón en el Antiguo Régimen, se aprecia, en los acuerdos nupciales, un gran esfuerzo por asegurar la posible viudedad de la esposa.

Palabras clave: Reino de Valencia, matrimonio, ascenso, mujeres, viudedad.

\begin{abstract}
Thanks to the analysis of several marriage contracts, testaments, feuds, powers and different documentation, we have built a brief summary of the matrimony process of the nobility, with its causes and consequences for women, in the 18th century Kingdom of Valencia. As these arrangements between families were one of the key elements in the consolidation and rise strategies, they gather a special attention and a detailed work prior to the wedding. The documentation shows different processes that strengthened the fathers' authority and the lineage rise priority. Moreover, given the Ancien Régime women's dependency on man, it can be seen, in the prenuptial agreements, a great effort to ensure the ulterior survival of the bride turn widow.
\end{abstract}

Keywords: Kingdom of Valencia, marriage, rise, women, widowhood.

\section{SUMARIO}

1. Introducción. 2. Vida, matrimonio y viudedad. 3. Consecuencias del matrimonio para la mujer noble. 4. Conclusiones.

1 Departamento de Historia, Geografía y Arte, Universitat Jaume I; aamores@uji.es

2 El presente artículo ve la luz gracias al programa VALi+d, de la Generalitat Valenciana. Asimismo, se enmarca dentro del proyecto de investigación, financiado por la Universitat Jaume I, P1·1A2014-13 «De pequeños hidalgos a nobles titulados. Riquezas, poder y redes clientelares de la nobleza mediterránea». 


\section{Introducción}

Las nupcias, al margen de su gran importancia y repercusión social, marcaban para las mujeres nobles del Antiguo Régimen diversos ámbitos de su vida, estando siempre ésta condicionada en función del hombre al que se veían adscritas. Pasar de la figura del padre a la del esposo les suponía un notable cambio, al igual que también lo suponía para ambas familias implicadas. En la firma de los capítulos matrimoniales se plasmaban las aspiraciones de ascenso de las Casas, y se acordaba el régimen bajo el que viviría la nueva esposa, tanto durante la vida del marido como tras la muerte de éste, en su viudez.

A lo largo de las siguientes líneas pretendemos mostrar el resultado de un trabajo durante el cual hemos analizado diferentes matrimonios, pleitos, súplicas y demás documentación que nos ha permitido extraer ciertas conclusiones acerca del matrimonio en el Reino de Valencia a lo largo del último siglo del Antiguo Régimen. Para ello, hemos recorrido la Casa de los condes de Cirat a lo largo de la centuria, accediendo así a enlaces de familias asociadas a éstos, que han servido para completar las perspectivas adoptadas.

Sin embargo, si bien hemos realizado un estudio en profundidad y bajo la perspectiva de género dentro de los casos presentados, no se trata éste de un análisis que abarque gran número de familias, -principalmente debido a los márgenes del presente texto- sino una contribución más que se apoya en investigaciones previas, como son los trabajos de Benítez Sánchez-Blanco, Catalá Sanz o Ruiz Torres. Asimismo, pese a que todas las figuras mostradas se encuentran emparentadas de uno $\mathrm{u}$ otro modo, nos hemos decantado por estructurar el texto en función de los grandes aspectos generales que influyen en el modo en el que contemplamos la documentación: las negociaciones y pacto de los fundamentales capítulos matrimoniales por un lado-con repercusiones antes y después del matrimonio- y las consecuencias para la mujer, hija, que se convertía en esposa, por otro.

\section{Vida, matrimonio y viudedad}

El matrimonio suponía para las mujeres, dentro de la doctrina hegemónica del Antiguo Régimen, el punto clave y vital de su vida. Sin embargo, no sólo se trataba de un hecho de importancia capital para ellas, sino también para la familia, que incluía los esponsales en sus estrategias de ascenso, planificadas con gran antelación y precisión; lo cual llevaba al establecimiento de redes familiares y clientelares (Chacón Jiménez y Méndez Vázquez, 2007: 62). Las negociaciones y las preparaciones previas por ambas partes podían prolongarse en el tiempo, hasta que cantidades y condiciones quedaban acordadas y sancionadas ${ }^{3}$. Muestra de ello dan los diferentes capítulos matrimoniales consultados, donde las diferentes cifras mencionadas implican todo un proceso previo de consideración y análisis, dentro de los diferentes bienes y riquezas de la familia.

3 Este fenómeno distaba de producirse exclusivamente en la aristocracia o clases emergentes, sino que era así incluso para aquéllas familias que no pertenecían a un estamento privilegiado y, por tanto, sus bienes eran más limitados (Baldellou Monclús y Salas Auséns, 2016: 91). 
El grado de minuciosidad y concreción de los capítulos matrimoniales, donde hallamos un detallado y frecuente uso de cantidades cuyo origen llega a remontarse varias generaciones, muestra la importancia con la que se abordaban y seguían los procesos nupciales. Máxime cuando la familia era la responsable de dotar a la hija, punto clave de la planificación económica nobiliaria familiar, y consecuencia, en numerosas ocasiones, de un esfuerzo especialmente consciente e importante por parte de éstas (Catalá Sanz, 1993: 171; Atienza Hernández, 1986: 167).

Uno de los puntos que demuestra el elaborado grado de planificación implícito en el proceso matrimonial es el énfasis realizado en la obtención del caudal necesario para la composición de la dote. También es motivo de antelación y esfuerzo el creix, es decir, la aportación económica al enlace por parte del prometido, que suponía habitualmente la mitad del total de la dote y que se entendía como una «compensación del marido por la virginidad de la futura esposa» (Martínez Roda, 2014: 114).

Es necesario tener en cuenta, a su vez, el hecho de que conforme nos aproximamos a las postrimerías del setecientos, la crisis -económica, identitaria, social- de la nobleza crece en importancia. Por ello, sus dificultades aumentan conforme lo hace su precariedad financiera, muy dependiente de la inflación y devaluación, así como de la gran cantidad de deudas fruto de su nivel de vida (Ruiz Torres, 1988: 143). Consecuentemente, no resulta extraño que conforme avance el siglo se presten mayores atenciones, si cabe, a la materia económica de los enlaces.

Con tal de hacer frente y reunir el capital necesario para financiar estas oportunidades de ascenso que eran los matrimonios, las familias de la aristocracia recurrían a todo tipo de bienes, entre los que destacan aquellos transmitidos por generaciones gracias a la institución del mayorazgo ${ }^{4}$. Las dotes, en numerosas ocasiones, ya fuese en el momento de realizar el matrimonio o cuando eran restituidas a la esposa, venían financiadas gracias a la enajenación de parte de estas herencias. Si bien esta práctica ha sido constatada desde inicios de la Edad Moderna, la Nueva Planta había alterado su funcionamiento en el Reino de Valencia, donde a partir de entonces era necesario el permiso real para extraer rentas de ellos (Catalá Sanz, 2011: 65-66).

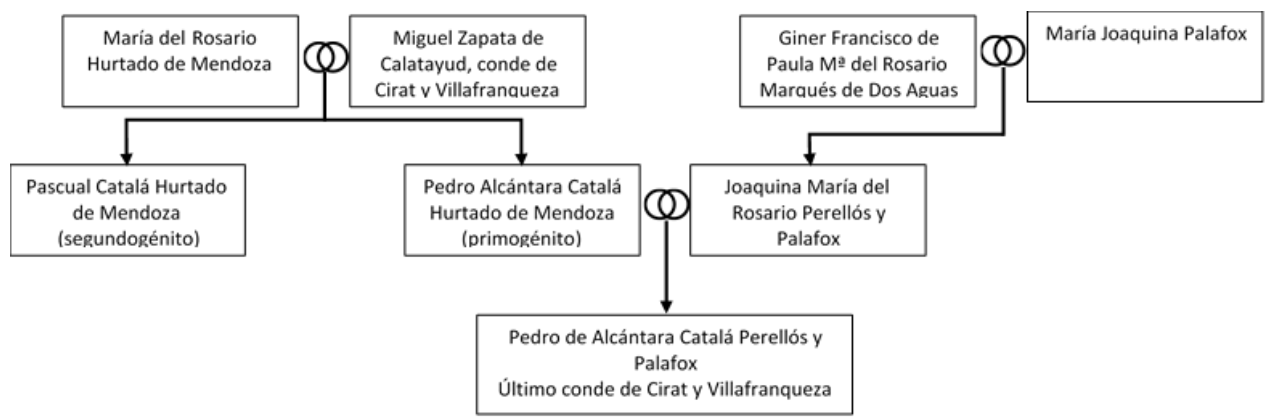

Figura 1: Árbol familiar simplificado del matrimonio entre don Pedro de Alcántara Catalá y doña Joaquina María del Rosario Perellós. Elaboración propia en base a ADC DCC 2351 y ADC DCC 17101.

4 Una vez más, siendo un clásico de obligada consulta tras más de cuatro décadas de su publicación, remitimos a Clavero, Bartolomé (1974): Mayorazgo: propiedad feudal en Castilla (1369-1836), Siglo XXI, Madrid. 
Sucede de este modo en los matrimonios analizados, si bien la obligación de bienes, rentas o mayorazgos se produce con la misma frecuencia en los casos de la restitución de la dote, arras y pensión de viudedad para la esposa que en la constitución y entrega de aquélla. Así resulta en el caso de las nupcias acordadas entre doña Joaquina María de Perellós, hija de los marqueses de Dos Aguas (don Giner Francisco de Paula María del Rosario Rabasa de Perellós y doña María Joaquina Palafox) y don Pedro de Alcántara Catalá, hijo de los condes de Cirat (don Miguel Catalá Zapata de Calatayud olim Bernardo de Vilarig y doña María del Rosario Hurtado de Mendoza) $)^{5}$. Se trata éste de un enlace -cuyos capítulos matrimoniales fueron firmados en el año 1796, ya en la última década del siglo- entre dos familias que habían incrementado notablemente su posición en los últimos años. Los Rabasa de Perellós, marqueses de Dos Aguas, habían pasado de un precario estado económico a finales del XVII a una situación predominante gracias al recibimiento de diferentes e importantes herencias, alcanzando en 1772 la Grandeza de España de segunda clase (Guardiola y Spuche, 2004: 170; Catalá Sanz, 1995: 19, 250, 290291). Similar, si bien no tan radical, es el recorrido de los Zapata de Calatayud: en las postrimerías del seiscientos se sentaron las bases matrimoniales que les permitirían pasar a ser, ya en el siglo siguiente, condes de Cirat y Villafranqueza y alcanzar, también, la Grandeza de España -en igual calidad- en el año 1788 (López Amores, 2015: 50-51). No obstante, la diferencia económica entre ambas familias es manifiesta, percibiéndose también este factor en la dinámica de las relaciones y los documentos por ellas firmados: hacia el año 1766 las rentas de los marqueses de Dos Aguas cuadriplicaban a las de los condes de Cirat (Catalá Sanz, 1995: 16).

En los capítulos matrimoniales acordados entre ambas familias entra enjuego, una vez más, la cuestión de la futura pensión de viudedad de la esposa. A este respecto, influye notablemente el ya mencionado cambio en el proceso para poder enajenar de los mayorazgos tras la Nueva Planta, siendo necesario el permiso real. De este modo se transmitía la responsabilidad del cumplimiento de este ineludibleaspecto a la parte interesada, es decir: la familia de la futura esposa. Este traspaso de responsabilidad -respecto a una pensión de la cual dependería la mujer en caso de enviudar- se hace de un modo explícito en los mismos capítulos matrimoniales:

se obligan dichos excelentísimos señores conde de Cirat e hijo, a impetrar el obtento de dicha facultad real. Y al mismo efecto conceden y atribuien el poder que más se necesite por derecho a la propia doña Joaquina de Perellós y excelentísimos señores marqueses de Dos Aguas, juntos o cada uno de por sí in solidum para que por sí por medio de legítimo apoderado comparescan ante Su Majestad, señores de su Real y Supremo Consejo de la Cámara, etcétera, en solicitud, y hasta obtener dicha Real Facultad, entendiéndose desde ahora para entonces consignadas las rentas de los citados mayorasgos, pudiendo cobrar de ellas dicha cantidad ${ }^{6}$.

5 Archivo de la Diputación de Castellón (en adelante ADC), DCC 2351 y ADC DCC 17101 . Remitimos a la Figura 1 para consultar el árbol general del enlace.

6 ADC DCC 1315 1. Para las transcripciones nos hemos decantado por una opción que, con pocas modificaciones, facilite la lectura y comprensión de las mismas. Así, hemos optado por desarrollar las abreviaturas, separar o unir las palabras que no se adecuan a una composición actual, normalización 
Se entregaba así buena parte de la responsabilidad de estos futuros pagos a la rama política de la familia, con lo que ante cualquier incumplimiento o desavenencia, se generaban pleitos y reclamaciones. Tal y como resulta lógico en el caso recién planteado, una vez finalizado el acuerdo matrimonial, el marqués de Dos Aguas y su hija, doña Joaquina, acudieron al Consejo Real con tal de obtener el permiso para poder extraer del patrimonio vinculado, lo cual fue aprobado siempre y cuando permaneciese dentro de la sexta parte de la renta líquida de los mismos mayorazgos poseídos por su esposo. ${ }^{7}$ A este respecto, es fundamental recordar que la manutención de una viuda podía llegar a suponer una fuerte carga para las arcas nobiliarias, que condicionaban tanto su economía como la propia constitución de las dotes. Con mayor énfasis cuando, ya hacia finales de siglo, la mayoría de las familias nobles valencianas se encuentran en disposición de enfrentarse a los nuevos cambios de paradigma y se aproximan a la crisis del Antiguo Régimen (Catalá Sanz, 1995: 305, 313-314).

Pasados algunos años tras la celebración de su matrimonio, la hija del marqués de Dos Aguas y esposa de don Pedro de Alcántara, sucesor al condado de Cirat y Villafranqueza, se ve en disposición de reclamar las mencionadas pensiones y devoluciones. Su esposo había fallecido el 13 de febrero de 1797, apenas un año después de ser padre del futuro heredero: don Pedro de Alcántara Catalá ${ }^{8}$ Tras haber enviudado, doña Joaquina de Perellós recibió lo estipulado por los capítulos matrimoniales: 3.500 libras valencianas por sus alimentos y el derecho a habitar una de las casas de Valencia del conde sin pagar alquiler alguno. Aparentemente, doña Joaquina pudo disfrutar de estos derechos al enviudar, en buena medida y según creemos a tenor de la documentación consultada, debido a continuar con vida el padre de su difunto marido, don Miguel Zapata de Calatayud. Sus problemas parecen comenzar con la muerte de su suegro en 1801, donde entra en juego la herencia del mismo, complicando notablemente las relaciones familiares. Se inician así una serie de reclamaciones ante el hermano de su esposo y, por tanto, cuñado: don Pascual Catalá, que se había negado a satisfacer por entero algunos puntos de los acordados en los capítulos matrimoniales ${ }^{9}$. El eje sobre el que se articulaba la discordia entre ambos giraba, precisamente, en torno a la herencia dejada por el anterior conde, donde la mencionada enajenación sobre los bienes de sus mayorazgos pasaba a ser uno de los principales argumentos en contra de la reclamante ${ }^{10}$.

El cuñado de la viuda elaboraba su defensa de la herencia en base a diferentes aspectos de los mencionados capítulos matrimoniales, donde sostenía que, desde el momento de fallecer su esposo, doña Joaquina había estado disfrutando de los diferentes puntos acordados - es decir, habitar una casa en la ciudad de Valencia y la pensión de viudedad- los cuales debían entrar dentro de la sexta parte de las ren-

de las mayúsculas y minúsculas, acentuación actualizada, introducción de los signos de puntuación básicos para la comprensión, regularización de grafías similares como «u»y «v»y, por último, conservación de la ortografía original, incluso -si aplica- en las abreviaturas desarrolladas.

7 ADC DCC 13162.

8 ADC, DCC 2351.

9 ADC DCC 13162.

10 ADC DCC 13162. 
tas de los mayorazgos y, en caso de excederlo, esta cantidad excedente debía descontarse de la herencia correspondiente al hijo de doña Joaquina, antes de proceder a pagar las cantidades exigidas. También añadía diversas quejas y matizaciones a la hora de afrontar la devolución de las arras: según la legislación foral y diversos tratadistas citados en la documentación -tales como el notario José Febrero o el jesuita Tomás Sánchez de Ávila, en su tratado De sancto matrimonii sacramento ${ }^{11}$ - cuando el padre otorga esta cantidad al matrimonio, debe ajustarse a una décima parte de lo que su hijo puede heredar de él ${ }^{12}$.

Las intenciones, por tanto, del cuñado de doña Joaquina de Perellós no conciernen tanto a la naturaleza de lo acordado en su matrimonio, sino a la herencia que podría recibir de su difunto padre. Una vez más, los capítulos matrimoniales se convierten así en un arma a esgrimir en el clásico escenario de la disputa por herencias. Don Pascual pretendía que las reclamaciones de la viuda se extrajesen de la parte correspondiente de su sobrino (en esos momentos, nuevo conde de Cirat y Villafranqueza), con tal de poder recibir, de este modo, un montante superior tras la muerte de su padre.

Este caso presentado no es el único -dentro de los matrimonios vinculados a la casa de Cirat- que recurre a la enajenación de los bienes con tal de asegurar las futuras pensiones de viudedad ${ }^{13}$. También sucede así en el matrimonio acordado entre don Juan Bautista Catalá y doña Ana María de Zapata y Calatayud, hija del conde de Cirat don Gaspar de Calatayud y doña Teresa Civerio Folch de Cardona. Pese a la próxima edad de ambos, al menos para los estándares del Antiguo Régimen (él era nacido en el año 1684 y ella en 1691) en las capitulaciones matrimoniales se obligan los bienes vinculados con tal de poder extraer de ellos las 300 libras que suponen la pensión de la futura viuda ${ }^{14}$. Los esponsales se celebraron en el año 1718, para los cuales don Juan Bautista Catalá aportó 3.000 libras en arras y recibió una dote por doña Ana María Zapata de Calatayud establecida en 8.000. Además, se acordó la cantidad de 200 libras anuales en gastos de cámara (Catalá Sanz, 1995: 291, 294).

Se aprecia en el presente ejemplo, sin embargo, un hecho que pone de manifiesto uno de los puntos de presión ejercidos por el marco patriarcal moderno sobre la mujer, particularmente sobre las viudas, estado especialmente preocupante para los moralistas debido a su mayor margen de «libertades» en el sistema. Es en los escritos de éstos donde se aprecia el fuerte condicionamiento social y moral que se ejercía sobre las viudas y donde se instaba a que la esposa, en caso de fallecer su

11 Así lo estipula en el libro VI: «De donation. inter coniuges», disputatio XXIX, número 18: «Tandem infertur, quàm inepte sponsi, dum assignatur per parentes dos sponsae, timentes ne excedat meram signatam in curiis Matriti, [...] petant tertium'constituere dotem sponsae: \& similiter ipsae sponsae timentes ne arrhae promissae à uiro excedant decimam bonorum, postulent tertium quendam eas promittere: si enim tertius ille ex propriis bonis dotem, aut arrhas constitueret, licitum esset (ut dixit in praec.) Cùm tamen ex propriis bonis nunquam id faciat, manifesta est fraus, \& iniustitia» (Sánchez, 1672: 431-432).

12 ADC DCC 13162.

13 Para facilitar la comprensión y relaciones entre los diferentes nombres presentados a continuación, remitimos a la Figura 2.

14 ADC DCC 351 y ADC DCC 2351.

ASPARKÍA, 30; 2017, 51-67 - ISSN: 1132-8231 - DOI: HTTP:/ / DX.DOI.ORG/10.6035/AsPARKIA.2017·30.3 
marido, permaneciese fiel a su memoria sin volver a casar (Bermejo Hernández, 1988: 185-187; Bolufer Peruga, 2010: 222-224). Es necesario puntualizar, por supuesto, que cuanto mayor fuese el estatus y la influencia de la viuda, mayor eran sus posibilidades de contravenir las imposiciones sociales, fuesen éstas del carácter que fuesen (Coolidge, 2007: 208-210).

En el caso de las 300 libras que don Juan Bautista Catalá prometía a doña Ana María de Zapata y Calatayud, no nos hallamos ante una excepción. Se obligaban los mayorazgos con tal de asegurar la pensión, pero se explicita de forma habitual que ésta se entregará "por todos los días de su vida, conservando viudez y no pasando a otro estado, aunque sea el de religión» ${ }^{15}$. Es decir, en caso de que doña Ana María contrajese matrimonio por una segunda vez, perdería su derecho a recibir la pensión de viudedad de su primer enlace. Esta situación no es en absoluto sui generis, pues a nivel general -tanto en la península como en otros estados europeos- se penalizaban las segundas nupcias de las viudas, principalmente dentro del primer año de viudedad: el llamado any de plor en el Reino de Valencia, aunque las limitaciones legales y económicas no se limitaban exclusivamente a éste (Benítez Sánchez-Blanco, 1992: 58; Guillot Aliaga, 2001: 282-283). Estas circunstancias y limitaciones afectaban principalmente a las mujeres, lo que se refleja, a su vez, en los datos de otros estudios concernientes a los nuevos enlaces de los viudos y las viudas, siendo más frecuentes las segundas nupcias de los varones, pues se encontraban más libres a la hora de contraer nuevos matrimonios, al contrario que ellas (Bideau, 1980: 33-35).

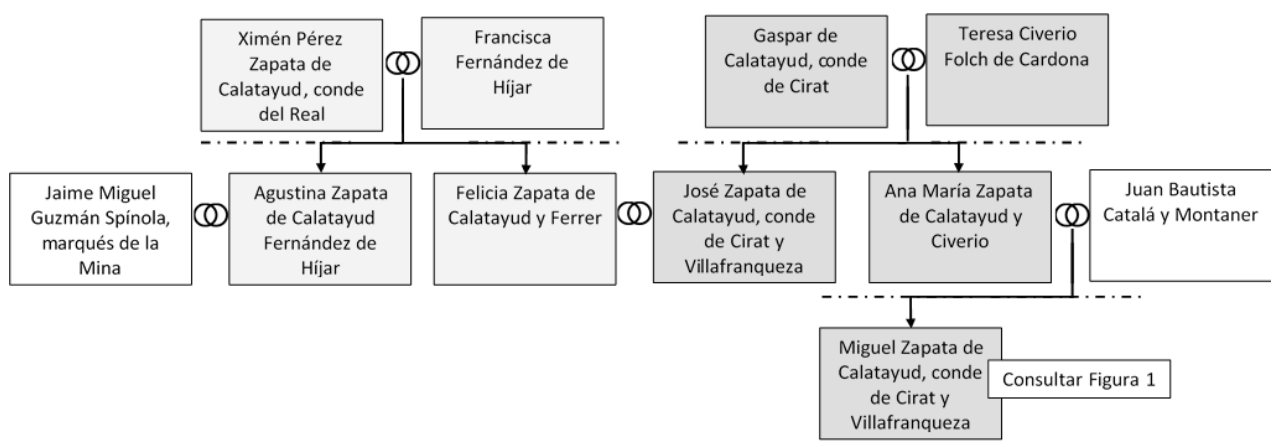

Figura 2: Árbol simplificado de los matrimonios mencionados de la casa de los condes de Cirat y la de los condes del Real. Elaboración propia en base a SNOAHN, FERNÁN NÚÑ̃ZZ, C2118, D10; SNOAHN, FERNÁN NÚÑEZ, C16, D9, ADC DCC 1311 y ADC DCC 2351.

Un hermano de doña Ana María casaría con otra rama de los Zapata de Calatayud valenciana, es decir, la Casa de los condes del Real: don José Zapata de Calatayud -que sería también conde de Cirat y Villafranqueza- contrajo así matrimonio con doña Felicia Zapata de Calatayud y Ferrer, hija de Ximén Pérez Zapata de Calatayud y doña Francisca Fernández de Híjar ${ }^{16}$. En estas uniones se continúa

16 Sección Nobleza Archivo Histórico Nacional (en adelante SNOAHN), FERNÁN NÚÑEZ, C2118, 
evidenciando el desempeño de una estrategia matrimonial concreta, por cada una de las respectivas familias involucradas, pues el destino de una de ellas influirá en las demás, principalmente después del reparto de las herencias.

Uno de los matrimonios más ventajosos que se realizaron en la señalada generación fue, precisamente, para con una de las hermanas de la mencionada doña Felicia Zapata de Calatayud, de nombre Agustina, que casó con don Jaime Miguel de Guzmán Spínola, marqués de la Mina ${ }^{17}$, el 17 de abril de 1733 en la ciudad de Valencia. Era éste un personaje de gran importancia, pues aunaba los cargos, entre otros, de «theniente general de los exércitos de Su Magestad cathólica, comandante general del Reyno de Aragón y presidente en su Real Audiencia de la Ciudad de Zaragoza». Estas ocupaciones provocaban que el servicio militar en la península italiana le tuviera ocupado en el momento de las nupcias, debiendo otorgar plenos poderes a don Juan Luis López, II marqués del Risco ${ }^{18}$, para la negociación de los términos del enlace. Asimismo, y debido a la ausencia de don Jaime Miguel de Guzmán, cuya residencia radicaba en Italia, también otorgó poderes adicionales al marqués del Risco para que contrajera las nupcias en representación suya ${ }^{19}$.

Para constatación de lo dicho anteriormente al respecto de las facilidades o dificultades de uno y otro género para contraer matrimonio en diferentes ocasiones, el marqués de la Mina había enviudado recientemente de su primera mujer, doña María Francisca Funes de Villalpando, y poco después ya se establecían los planes para su siguiente matrimonio. Su segunda esposa, doña Agustina, permanecería en el estado de viudez hasta su fallecimiento en febrero de 1789 , cumpliendo con rigor con la normativa social de la época ${ }^{20}$.

El matrimonio entre ambos supone otro ejemplo de un enlace planeado hasta el detalle. Y, como afirmábamos anteriormente, un punto de contacto de gran importancia, no sólo entre los contrayentes, sino también -O, más bien, sobre todo- para las dos familias involucradas. Así, los desposorios implicaban habitualmente las haciendas de ambas Casas, y abrían las puertas al establecimiento de redes y alianzas, al mismo tiempo que, en ocasiones, también suponían el estallido de disputas (Pla Alberola, 1987: 113-114).

El montante total de la dote entregada por la familia de los condes del Real al marqués de la Mina sería de 31.772 libras, 17 sueldos y 5 dineros y medio en moneda valenciana ${ }^{21}$. Una cantidad en absoluto despreciable si la comparamos con las aportadas en otros matrimonios de la nobleza del Reino de Valencia e, incluso,

D10; SNOAHN, FERNÁN NÚÑEZ, C16, D9 y ADC DCC 2351.

17 Para más información sobre este reputado y conocido personaje, remitimos a una obra de reciente publicación: Barea Amorena, Ernesto (2016): Jaime de Guzmán y Spinola, Capitán General de Cataluña, II marqués de la Mina, Alicante, Editorial Club Universitario.

18 Natural de Huencavelica, Perú, donde su padre, primer marqués y conocido por ser autor de numerosas obras de derecho e historia, desempeñó las labores de gobernador (Muro Orejón, 1946: 788-793).

19 SNOAHN, FERNÁN NÚÑEZ, C2118, D10 y Archivo Histórico Nacional (en adelante $A H N$ ), OMEXPEDIENTILLOS, N. 12029.

20 SNOAHN, FERNÁN NÚÑEZ, C2290, D7.

21 SNOAHN, FERNÁN NÚÑEZ, C2118, D10.

ASPARKÍA, 30; 2017, 51-67 - ISSN: 1132-8231 - DOI: HTTP:/ / DX.DOI.ORG/10.6035/ASPARKIA.2017.30.3 
si se coteja con la aportada en el caso de la propia hermana de doña Agustina, de nombre Inés, que casó con don Juan José Azlor, conde de Guara, entregando como dote 21.773 libras (Catalá Sanz, 1995: 294-298). Esta diferencia indica con precisión la ventaja de las nupcias acordadas, para las cuales los padres de la esposa condicionaron diferentes bienes, en un proceso cuidadosamente planificado.

En el caso de doña Agustina, se trata de una dote adventicia, es decir, conformada en su gran mayoría por bienes que provenían de la rama materna de la familia, lo cual no resultaba extraño y, pese a ser la dote deber del padre, se solían incorporar a menudo los bienes parafernales de la madre (Catalá Sanz, 1995: 296-297; Benítez Sánchez-Blanco, 1992: 61). Se reunió así una notable cantidad, a través de diferentes donaciones y herencias, realizadas por los familiares más acaudalados en el momento de su fallecimiento. En primer lugar, el conde del Real restituye la dote de doña Francisca Fernández de Híjar, su esposa y madre de doña Agustina, a la cual corresponde, por ser una de los cuatro herederos dejados por aquélla, un total de 21.772 libras, 17 sueldos y 5 dineros y medio en moneda valenciana, con lo cual se conformaban ya más de dos tercios del total de la dote ${ }^{22}$.

Llegados a este punto, puede llamar especialmente la atención la fuerte diferencia entre la dote de doña Agustina y la de su madre que, incluso dividida entre cuatro herederos, supone una cifra elevada en relación a los otros matrimonios del momento. La notable dote de ésta, doña Francisca Fernández de Híjar, que contrajo matrimonio en el año 1699, vino constituida básicamente por dos personajes: en primer lugar, el padre de ésta, don Luis Fernández de Hijar, conde de Belchite; en segundo, por otra mujer, la duquesa de la Palata y princesa de Massa, doña Francisca Toraldo y Aragón, su abuela ${ }^{23}$. Compuesta por diferentes bienes, la aportación de ambos al matrimonio con el conde del Real constaba de:

Ciento diez y ocho mil setecientos sessenta y un ducados de vellón, un real y doce maravediz y medio, esto es: veinte y siete mil ocho cientos ducados de vellón en un duro o censo sobre la villa de Madrid; mas diez y siete mil quarenta y cinco ducados de vellón y seis reales, en un legado de diez mil libras jaquesas de la dicha señora condesa de Belchite, hecho a favor de la referida señora condesa de Real; mas treinta y dos mil setecientos veinte y siete ducados de vellón y tres reales, en un vale de seis mil doblones firmado por Melchor Bannobe; y los restantes quarenta y un mil ciento ochenta y ocho ducados de vellón, cuatro maravediz y medio en joyas, plata labrada, perlas, oro y alajas ${ }^{24}$.

Realizando una sencilla equivalencia entre los ducados de vellón y la moneda valenciana calculamos que el total de la dote de doña Francisca Fernández de Híjar fue de, aproximadamente, 87.091 libras, 9 sueldos y 10 dineros. Cantidad que, enmarcada en el entorno económico matrimonial del siglo XVIII destaca sobremanera, mientras que, contextualizada en el régimen dotal del XVII -el siglo con ma-

23 Remitimos a la Figura 3 con tal de poder ver un desglose simplificado de las dotes de doña Agustina Zapata de Calatayud y su madre, doña Francisca Fernández de Híjar.

24 SNOAHN, FERNÁN NÚÑEZ, C2118, D10. 
yores cifras en lo que a dotes se refiere de toda la Edad Moderna (Catalá Sanz, 1993: 171-175) - y en el rango de la más alta nobleza, se sitúa entre las más engrosadas.

Por tanto, y con tal de ilustrar la meticulosidad con la que se estructuraba el ingente pago de las dotes en la nobleza, la gran aportación que en su momento realizó doña Francisca Toraldo y Aragón, duquesa de la Palata, vendría a financiar, treinta y cuatro años más tarde, más de dos terceras partes de la dote de su bisnieta, doña María Agustina Zapata de Calatayud, en unas nupcias claramente ventajosas. Para completar la cantidad, el conde del Real añadiría 10.000 libras valencianas adicionales de sus propios bienes, lo que unido a las 21.772 libras, 17 sueldos y 5 dineros y medio conformaron el total definitivo aportado por la familia de la esposa al matrimonio con el marqués de la Mina.

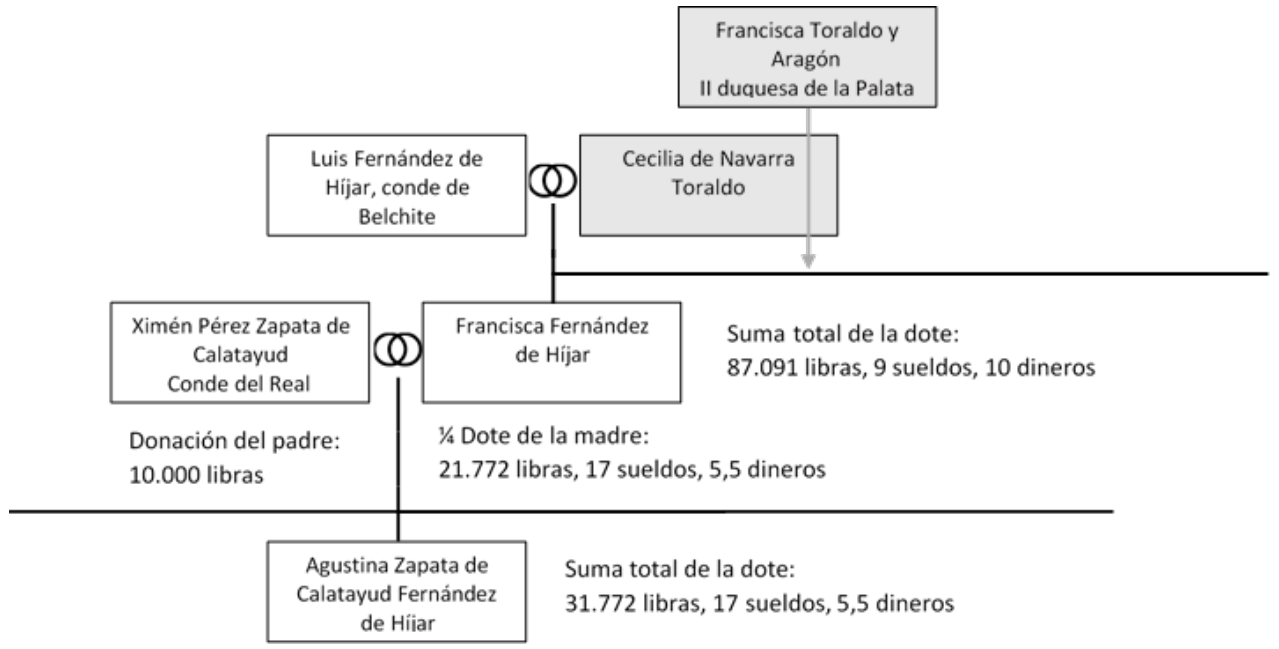

Figura 3: Diagrama familiar con las herencias y donaciones que constituyeron la dote de Agustina Zapata de Calatayud Fernández de Hijar y su madre. Elaboración propia en base a SNOAHN, FERNÁN NÚÑ̃Z, C2118, D10.

A la luz de estas cantidades, podemos apreciar que la dote aportada en el matrimonio de la hermana de doña Agustina, doña Inés, mencionada anteriormente, equivale a esta misma suma, es decir, a un cuarto de la dote de la madre de ambas, doña Francisca Fernández de Hijar. Este hecho permite deducir, por un lado, que el descenso de estos valores hacia el siglo XVIII permitió el dotar a varias hijas de un modo acorde a su posición y, por otro lado, que la donación adicional de 10.000 libras valencianas realizada por el conde sirvió para capacitar el enlace de doña Agustina con una familia de mayor abolengo, como era la del marqués de la Mina. Es en estas maniobras donde se muestran las estrategias concebidas por la Casa y la gestión económica que en ellas se hace, así como el alcance y la transferencia durante generaciones que pueden llegar a tener los grandes pagos afrontados por las familias de la aristocracia, como eran dotes o pensiones de viudedad.

Al igual que sucedía en los casos presentados anteriormente, el marqués de la Mina se comprometió - $\mathrm{O}$, más bien, el marqués del Risco, en su lugar- a «obligar», 
es decir: comprometer, todos sus bienes que fuesen necesarios con tal de asegurar, llegado el caso, la restitución de la dote, las arras y los derechos de viudedad. Asimismo, también daba palabra de pedir el permiso real para poder extraer capital, si no fuese suficiente con sus otros bienes, de sus mayorazgos, encomiendas e, incluso, de su sueldo como militar ${ }^{25}$. No es de extrañar que se tratase de «asegurar» con tanto ahínco estos sueldos, materia en la que sin duda debía estar implicada la familia de la futura esposa, pues la viudedad era un estado que, para las mujeres de la nobleza, implicaba mayor rango de maniobrabilidad tanto a nivel social como económico, pero acarreaba también una serie de posibles dificultades que podían tornar la existencia de la viuda mucho más precaria de lo esperado para una familia de la aristocracia (Guillot Aliaga: 2001: 269). Además, el interés con tal de implicar al marqués de la Mina para que comprometiese mayorazgos y sueldos, entre otros bienes ${ }^{26}$, era mayor cuanto mayores resultaban los derechos de viudedad. En los capítulos matrimoniales, don Jaime Miguel de Guzmán se comprometía a entregar a su esposa 330 libras al año en caso de la restitución de las arras hasta el fin de sus días, y 1.200 libras al año como pensión de viudedad mientras conservase este estado. Así, se entiende nuevamente la fuerte vinculación existente entre el establecimiento del matrimonio y la viudedad, que como mencionamos más arriba, era legitimada por el propio esquema social. Ya fuese por estas razones o por otras, doña María Agustina quedaría viuda y permanecería sin volver a contraer esponsales hasta su muerte ya en las postrimerías del siglo ${ }^{27}$.

Es hacia el final de los capítulos matrimoniales, en la octava condición que se describe, donde se puede hallar la pieza que hace encajar, perfectamente, el enlace acordado, el esfuerzo económico y las propias estrategias de ascenso y consolidación de la familia. Así, se establecía que doña Agustina, «se da por contenta y satisfecha de todos los derechos y acciones que tiene y le pueden pertenecer en los bienes dotales que trajo en su capitulación matrimonial o en qualquiera otra manera», por lo que, en la práctica, renunciaba a cualquier otra herencia que le pudiese corresponder. Al mismo tiempo, se estipulaba que: «dicha renuncia la hace dicha señora doña María Agustina en favor del señor don Francisco Zapata de Calatayud Fernández de Hijar, primogénito del dicho conde de Real, su hermano» ${ }^{28}$. En definitiva, la futura esposa del marqués de la Mina no podría recibir ninguna herencia adicional, más allá de las acordadas en su dote, y cualquier herencia que pudiera haber recibido, recaía así sobre el primogénito, don Francisco Zapata de Calatayud.

Con ello, se matizaba enormemente el esfuerzo económico realizado al dotar a la hija, pues, si bien se aseguraba la familia de que ésta tuviese asegurada su posición como esposa y unas pensiones de viudedad adecuadas, se priorizaba la capacidad de heredar del primogénito, lo que formaba parte clave de la estrategia

25 SNOAHN, FERNÁN NÚÑEZ, C2118, D10.

26 También obligó cantidades pendientes de resolución en pleitos, diferentes objetos de gran valor como vajillas de plata o tapices, junto a las rentas de varios palacios italianos en disputa con otros miembros de su familia.

27 SNOAHN, FERNÁN NÚÑEZ, C2290, D7.

28 SNOAHN, FERNÁN NÚÑEZ, C2118, D10. 
básica de muchas Casas de la aristocracia. El propio don Francisco, por ser hermano de la futura esposa y por estar directamente implicado en el resultado del enlace fue uno de los firmantes, además de mostrar su conformidad con entregar parte de la dote en un censo al que también tenía derecho, prometía «no hir en tiempo alguno contra lo contenido en aquél [el capítulo que le competía] bajo la obligación que hace de sus bienes havidos y por haver» ${ }^{29}$. Con ello, se prueba que el acuerdo de unas nupcias distaba de afectar de un modo exclusivo a la pareja prometida, sino que involucraba extensivamente a todo el núcleo familiar, pudiendo con facilidad propagar e implicar a otros miembros adicionales.

Esta práctica, basada en la constitución de una buena dote y la exclusión de la herencia de la esposa existía, al menos, desde la Baja Edad Media; sin embargo, en territorios como el Reino de Valencia no resultaba especialmente frecuente (Catalá Sanz, 1995: 181; Furió, 1990: 323). A este respecto, la autoridad del paterfamilias resultaba casi absoluta, aumentando conforme avanzaba el siglo XVIII, pues, si ya en la etapa foral podía excluir libremente a cualquiera de sus herederos de la legítima -en ocasiones como recurso a no seguir las estrategias matrimoniales establecidas por la Casa-, a partir de la Pragmática Sanción de 1776 los hijos e hijas que desobedecían la autoridad paterna a la hora de contraer matrimonio venían directamente excluidos de cualquier herencia, sin poder realizar reclamación alguna (Chacón Jiménez y Méndez Vázquez, 2007: 63-66; Pla Alberola, 1987: 116-117).

Es precisamente un conde de Cirat, don Miguel Catalá Zapata de Calatayud ${ }^{30}$, una figura que tomará la decisión de este corte, excluyendo a su hija Ana María de la herencia, tras aportar a su enlace una dote de 20.000 pesos (Catalá Sanz, 1995: 181). Sin embargo, este conde de Cirat y Villafranqueza también había entrado en un pleito por la obtención de un mayorazgo para su hija, procedente de la rama familiar de su primera esposa, doña Antonia Gil Delgado. De este modo, doña Ana María casaría en el año 1788 con don Antonio Martínez de Medinilla, recibiendo la dote acordada, un mayorazgo secundario fundado en 1598 por Gerónimo Meneses en la ciudad de Burgos y la exclusión de cualquier posible otra herencia, que quedaría para la rama fundada en el matrimonio de su segunda esposa, doña María del Rosario Hurtado de Mendoza ${ }^{31}$.

Es así como se imbrican diferentes aspectos que coadyuvan para conformar una estrategia o dinámica familiar que impera entre las diferentes prioridades individuales de sus miembros. En ella, recursos como las diferentes dotes que una familia preveía aportar, las herencias y mayorazgos disponibles provenientes de sus diferentes miembros -en ocasiones desde varias generaciones precedentes-, la victoria sobre pleitos y otros litigios, componen un conjunto, no limitado exclusivamente a estos factores, que ilustra la fuerte vinculación existente entre la agenda matrimonial de una Casa y el patrimonio al que tiene acceso. Este punto ha sido puesto de relevancia desde hace

29 SNOAHN, FERNÁN NÚÑEZ, C2118, D10.

30 Hijo de los ya mencionados doña Ana María Zapata de Calatayud y don Juan Bautista Catalá, nacido el 1 de marzo de 1721. Sería su hijo, don Pedro de Alcántara, el que contraería matrimonio con la hija del marqués de Dos Aguas, doña Joaquina Perellós. ADC DCC 235 1. Consultar Figura 1 y Figura 2 para más información.

31 AHN, Consejos, leg. 31317, exp. 10; ADC DCC 2351.

ASPARKÍA, 30; 2017, 51-67 - ISSN: 1132-8231 - DOI: HTTP:/ / DX.DOI.ORG/10.6035/ASPARKIA.2017.30.3 
años gracias a las investigaciones que profundizan en la historia de la familia (Chacón Jiménez, 1987: 14). A ello debe añadirse la ampliación de fronteras que realizaban las Casas nobiliarias gracias a los matrimonios de las hijas, destinadas ora a la vida religiosa, ora a enlaces con personajes que favoreciesen el crecimiento de las redes familiares y clientelares de sus respectivas familias.

\section{Consecuencias del matrimonio para la mujer noble}

Tal y como hemos mostrado en las páginas precedentes, la constitución de los capítulos matrimoniales era un paso de alta importancia, tanto para la esposa y marido como para el resto de la familia implicada, donde se asentaban las bases económicas que reglamentarían buena parte de la vida de la mujer en el caso de que llegase al estado de viudedad; sin embargo, también dictaban las normas básicas que debían respetarse durante el matrimonio de la pareja.

Por ello no es de extrañar que en estos acuerdos entre familias se explicitasen las pensiones anuales de las cuales las esposas podrían disponer libremente, destinadas para su uso personal, las cuales venían denominadas como «alfileres o «gastos de cámara» (Catalá Sanz, 1995: 303) 32. Estas cuantías formaban parte, también, de las negociaciones emprendidas por las familias de las novias, donde influía de manera considerable el abolengo de su Casa de origen. En el referido matrimonio entre la hija de los condes del Real, doña Agustina Zapata de Calatayud y el conocido marqués de la Mina, se le otorgarían a aquélla 1.000 libras de moneda valenciana, sin expresar o aportar más datos al respecto ${ }^{33}$. Sin embargo, ya hacia finales de siglo, en los capítulos firmados entre el hijo de los condes de Cirat y Villafranqueza y la hija del marqués de Dos Aguas, hallamos una explícita referencia a que sea la esposa, y no el marido, la que administre con total independencia estas anualidades: «cuya cantidad ha de poder usar libremente como de cosa suya propia con independencia absoluta del expresado excelentísimo señor don Pedro, su futuro esposo y de otra qualquier persona» ${ }^{34}$.

Desconocemos si, a lo largo del siglo XVIII, se produce una pérdida de confianza en la solidez e individualidad de estas pensiones anuales, (ya que entre ambos matrimonios transcurren casi sesenta años); sin embargo, sí que se constata la existencia de una fuerte crítica de cariz misógino hacia la vida matrimonial. Destacan, sobre todo, los col-loquis, una versión valenciana de la literatura de cordel que hacía énfasis en la sátira en contra de la mujer, retratando a las novias y esposas de la época como despilfarradoras y holgazanas (Gomis Coloma, 2010: 258-262).

Por ello, no resulta extraño que tanto el padre como la madre de la esposa que también entregaban, en la mayoría de los casos, una cuantiosa dote, buscasen asegurarse de que su hija gozase plenamente de lo discutido y acordado en los capítulos matrimoniales.

Al contrario de lo que las sátiras del momento pudiesen indicar, las vidas de las esposas de la nobleza se encontraban cargadas de responsabilidades. Asimismo, con

32 ADC DCC 1351 1; SNOAHN, FERNÁN NÚÑEZ, C2118, D10.

33 SNOAHN, FERNÁN NÚÑEZ, C2118, D10.

34 ADC DCC 13151.

ASPARKÍA, 30; 2017, 51-67 - ISSN: 1132-8231 - DOI: HTTP:/ / DX.DOI.ORG/10.6035/AsPARKIA.2017.30.3 
la llegada del siglo XVIII, éstas no harán sino aumentar, permitiéndoles cosechar nuevas cotas de independencia y visibilidad que, si bien durante los siglos precedentes ya se daban en ocasiones, no lo hicieron con la frecuencia propia del Siglo de las Luces. Eran éstas mujeres:

informadas, con capacidad de decisión y resolución, visibles, que se hacen presentes elaborando reglamentos de cómo cobrar sus rentas, escribiendo ordenanzas municipales, designando cargos concejiles, vigilando la moral y las buenas costumbres en sus jurisdicciones, disciplinando y troquelando conductas, haciendo de intermediarias en los conflictos entre su Casa y vasallos díscolos, o actuando como «mater familias» que utilizando la vía de la petición y su respuesta, la merced, conceden limosnas, resuelven solicitudes y peticiones de socorro y servicio, pero que también, en esa misma función maternal, castigan comportamientos inadecuados a sus intereses (Atienza Hernández, 1992: 636).

Si bien muchas mujeres nobles alcanzaban este nivel de actividad e influencia con el paso a la viudedad, muchas de ellas ya habían desarrollado largamente sus competencias, bien durante su formación, o más a menudo durante el gobierno de las propiedades y señoríos, sobre todo durante las ausencias de los esposos. Ello hacía que, al fallecer, pudiesen ser designadas usufructuarias en las últimas voluntades del paterfamilias, lo cual formalizaba notablemente su rango de acción (Guillot Aliaga, 2001: 280-281; Fink De Backer, 2010: 114-122).

El gobierno de la mujer en ausencia del marido era algo que, dentro del marco patriarcal tradicional del Antiguo Régimen, se recomendaba, en buena medida para favorecer también el buen desempeño de la convivencia y del funcionamiento del hogar (Bolufer Peruga, 2010: 222-223). Es en este punto donde hallamos la situación de doña María Agustina Zapata de Calatayud. Dadas las notables ausencias de su esposo, don Jaime Miguel Guzmán Spínola, ella recibió, en el mes de octubre del mismo año de su boda (1733), todos los poderes necesarios para poder administrar y gobernar «su hazienda y bienes», en representación de la propia persona del marqués ${ }^{35}$.

En definitiva, eran varias las obligaciones que la esposa contraía en el momento de casar, favorecidas posiblemente en función de su educación, intereses y capacidades, así como de otros factores relativos a la vida marital, destacando principalmente el régimen de ausencias del marido. Junto a las escrituras de poderes se encontraban también los capítulos matrimoniales que, como hemos mostrado, fundamentaban aspectos esenciales como los gastos de cámara o las pensiones que podría recibir la mujer. Estos últimos, en caso de enviudar, se probarían de especial importancia, dada la acuciante necesidad que de ellos tenían las viudas.

\section{Conclusiones}

Conforme a lo expuesto previamente, podemos afirmar que existen una serie de pa- 
trones que en base a la documentación y bibliografía permiten realizar algunas reflexiones de carácter general y, por tanto, sujetas a variaciones y excepciones. Asimismo, y tal y como indicábamos al inicio de este texto, a lo largo del siglo son numerosos los cambios que acontecen, tanto a nivel social como dentro del propio estamento nobiliario, en clara situación de paulatina decadencia.

De todo ello, quizás el punto de mayor importancia sea, una vez más, el gran detalle existente en la elaboración de los capítulos matrimoniales. Es en ellos donde se vuelcan los intereses -tanto coincidentes como cruzados- de las Casas implicadas, y donde se vislumbran las aspiraciones de ascenso, expansión y consolidación de las mismas. Fruto del papel capital de estos contratos en los enlaces, se aprecia una continuidad en el uso de los bienes de las familias, empleando en las donaciones acordadas capitales procedentes de herencias o de antiguas dotes.

Asimismo, se evidencia un fuerte grado de conexión entre el acto matrimonial y el estado de la viudez para las mujeres. Durante los pasos previos a las nupcias y en las mencionadas negociaciones, se preparaba el marco legal que regiría las futuras condiciones de la mujer en caso de que premuriese su esposo, de modo que aquélla pudiese sobrevivir y, llegado el caso, mantener también a los/as posibles herederos/as. Era precisamente durante la viudedad cuando la mujer podía desvincularse, en cierta medida, de la figura masculina, pudiendo realizar acciones con mayor independencia, y simultáneamente, pasando a ser más vulnerable ante el propio sistema. Asimismo, esta independencia se desvanecía si contraían segundas nupcias, momento en el que volvían a estar adscritas a otro varón y perdían ciertas ventajas económicas como las pensiones de viudedad o, en algunos casos, el usufructo de los bienes del anterior esposo.

En definitiva, el arte del buen casar era, por un lado, el poder conceder a la propia hija no sólo un matrimonio digno y conforme a su estrato social, sino también el dotarla de una viudedad «asegurada» completamente blindada. Pero se trataba, al mismo tiempo, de conseguir que el enlace celebrado encajase perfectamente con las estrategias familiares del linaje que, en muchas ocasiones, pretendían favorecer la situación del primogénito varón y principal heredero. Con todo ello se esperaba ampliar las redes de las que disponía la Casa y, simultáneamente, facilitar también la aglomeración de poder y patrimonio dentro del cuerpo principal de la familia, gracias a la potente vinculación existente entre el paterfamilias y el primogénito.

\section{REFERENCIAS Y BIBLIOGRAFÍA}

Atienza Hernández, Ignacio (1986): «Las mujeres nobles: clase dominante, grupo dominado. Familia y orden social en el Antiguo Régimen». En: María Carmen GARcía-Nieto PARís (ed.): Ordenamiento jurídico y realidad social de las mujeres: siglos XVI a XX: actas de las IV Jornadas de Investigación Interdisciplinaria. Madrid: Seminario de Estudios de la Mujer, pp. 149-168.

- (1992): «De lo imaginario a lo real la mujer como señora/gobernadora de estados y vasallos en la España del Siglo XVIII». En: Arlette FARGE \& Natalie ZEMON DAvIS (eds.): Historia de las mujeres en Occidente, tomo 3. Madrid: Taurus, pp. 635-654. 
Baldellou Monclús, Daniel \& Salas Auséns, José Antonio (2016): «Noviazgo y matrimonio en Aragón. Casarse en la Europa del Antiguo Régimen», Revista de Historia Moderna. Anales de la Universidad de Alicante. No. 34, Alicante, Universidad de Alicante, pp. 79-105.

Benítez SÁNCHEZ-Blanco, Rafael (1992): «Familia y transmisión de la propiedad en el País Valenciano (siglos XVI-XVII): ponderación global y marco jurídico». En: Francisco Chacón Jiménez \& Juan Hernández Franco: Poder, familia y consanguinidad en la España del Antiguo Regimen. Barcelona: Anthropos, pp. 35-70.

Bermejo Hernández, María Ángeles (1988): «La imagen de la mujer en la literatura moral y religiosa de los siglos XVI y XVII», Norba. Revista de historia. N ${ }^{\circ}$. 8-9, Badajoz, Universidad de Extremadura, pp. 175-188.

BIdeAU, Alain (1980): «A Demographic and Social Analysis of Widowhood and Remarriage: the Example of the Castellany of Thoissey-En-Dombes, 1670-1840», Journal of Family History. V. 5, No. 1, SAGE, pp. 28-43.

Bolufer Peruga, Mónica (2010): «De madres a hijas, de padres a hijos: familia y transmisión moral (ss XVII-XVIII)». En: Joan BESTARD CAMPs \& Manuel PÉrez GARcía: Familia, valores y representaciones. Murcia: Universidad de Murcia, pp. 217-238.

Catalá SAnZ, Jorge Antonio (1993): «El coste económico de la política matrimonial de la nobleza valenciana en la época moderna», Estudis: Revista de historia moderna. $\mathrm{N}^{\mathrm{o}}$. 19, Valencia, Universitat de València, pp. 165-190.

- (1995): Rentas y patrimonios de la nobleza valenciana en el siglo XVIII. Madrid: Siglo XXI.

- (2011): «Integridad patrimonial, perpetuidad, memoria. Contradicciones de los mayorazgos valencianos en la época moderna», Studia historica. Historia moderna. No. 33, Salamanca, Universidad de Salamanca, pp. 61-95.

Chacón Jiménez, Francisco (1987): «La familia en España: una historia por hacer». En: CASEY, James et. al.: La familia en la España mediterránea (siglos XV-XIX). Barcelona: Editorial Crítica, pp. 13-35.

Chacón Jiménez, Francisco \& MÉndez VÁzquez, Josefina (2007): «Miradas sobre el matrimonio en la España del último tercio del siglo XVIII», Cuadernos de historia moderna. $\mathrm{N}^{\mathrm{o}}$. 32, Madrid, Universidad Complutense, pp. 61-85.

Coolidge, Grace E. (2007): «"A Vile and Abject Woman”: Noble Mistresses, Legal Power, and the Family in Early Modern Spain», Journal of Family History. V. 32, No. 3, SAGE, pp. 195-214.

FINK DE BACKER, Stephanie (2010): Widowhood in early modern Spain: protectors, proprietors, and patrons. Leiden: Brill.

Furió, Antoni (1990): «Tierra, familia y transmisión de la propiedad en el País Valenciano durante la Baja Edad Media». En: Reyna PAstor DE Togneri: Relaciones de poder, de producción y de parentesco en la Edad Media y Moderna. Madrid: Consejo Superior de Investigaciones Científicas, pp. 305-328.

Gomis Coloma, Juan (2010): «La sátira del matrimonio en pliegos sueltos y col-loquis del siglo XVIII». En: Joan Bestard CAmps y Manuel Pérez García: Familia, valores y representaciones. Murcia: Universidad de Murcia, pp. 257-268.

Guardiola y Spuche, Pascual (2004): Antiguos linajes del Reino de Valencia. Valencia: Real Academia de Cultura Valenciana. 
Guillot Aliaga, María Dolores (2001): «Derechos de la viuda en la Valencia foral», Hispania: Revista española de historia. V. 61, No. 207, Madrid, Consejo Superior de Investigaciones Científicas, pp. 267-288.

López Amores, Antonio (2015): «Desde el mito a la grandeza: auge de una rama valenciana de la casa "Zapata de Calatayud" (siglos XVI-XVIII)», Millars. Espai $i$ història. No. 38, Castellón de la Plana, Universitat Jaume I, pp. 37-56.

MARTínez RodA, Federico (2014): «El Derecho común y la supresión de los Fueros de Valencia», Revista de estudios políticos. N. 163, Madrid, Centro de Estudios Políticos y Constitucionales, pp. 101-124.

Muro Orejón, Antonio (1946): «El doctor Juan Luis López, marqués del Risco, y sus comentarios a la Recopilación de Indias», Anuario de historia del derecho español. No. 17, Madrid, Ministerio de Justicia, pp. 785-864.

Pla Alberola, Primitivo José (1987): «Familia y matrimonio en la Valencia moderna: apuntes para su estudio». En: CASEY, James et. al.: La familia en la España mediterránea (siglos XV-XIX). Barcelona: Editorial Crítica, pp. 94-128.

Ruiz Torres, Pedro (1988): «La aristocracia en el Pais Valenciano: la evolución dispar de un grupo privilegiado en la España del siglo XIX», Publications de l'École française de Rome. Roma, École française de Rome, pp. 137-163.

SÁNCHEZ, Tomás (1672): De sancto matrimonii sacramento disputationum. Venecia: Benedictum Milochum.

Recibido el 21 de noviembre de 2017

Aceptado el 22 de noviembre de 2017

BIBLID [1132-8231 (2017): 51-67] 